\title{
Profile of ocriplasmin and its potential in the treatment of vitreomacular adhesion
}

This article was published in the following Dove Press journal:

Clinical Ophthalmology

6 May 2014

Number of times this article has been viewed

\author{
Francisco R Stefanini ${ }^{1-3}$ \\ Maurício Maia' \\ Paulo Falabella ${ }^{1-3}$ \\ Marcel Pfister ${ }^{2,3}$ \\ Moritz Niemeyer ${ }^{2}$ \\ Amir H Kashani ${ }^{3}$ \\ Mark S Humayun ${ }^{3}$ \\ Michael J Koss ${ }^{2,3,4}$
}

'Retina Division, Department of Ophthalmology and Visual Sciences, Federal University of Sao Paulo, Sao Paulo, Brazil; '2Doheny Eye Institute, Los Angeles, CA, USA; ${ }^{3}$ Department of Ophthalmology, Keck School of Medicine of the University of Southern California, Los Angeles, CA, USA; ${ }^{4}$ Department of Ophthalmology, Goethe University, Frankfurt/Main, Germany
Correspondence: Francisco R Stefanini Doheny Eye Institute, I 355 San Pablo St, Unit 102, Los Angeles, CA 90033, USA

Tel + I 3234426575

Email frstefanini@gmail.com
Abstract: The recent approval by the US Food and Drug Administration of ocriplasmin for the treatment of symptomatic vitreomacular adhesion (VMA), often associated with vitreomacular traction (VMT) and macular hole (MH), has brought new attention to the field of pharmacologic vitreolysis. The need for an enzyme to split the vitreomacular interface, which is formed by a strong adhesive interaction between the posterior vitreous cortex and the internal limiting membrane, historically stems from pediatric eye surgery. This review summarizes the different anatomic classifications of posterior vitreous detachment or anomalous posterior vitreous detachment and puts these in the context of clinical pathologies commonly observed in clinical practice of the vitreoretinal specialist, such as MH, VMT, age-related macular degeneration, and diabetic macular edema. We revisit the outcome of the Phase II studies that indicated ocriplasmin was a safe and effective treatment for selected cases of symptomatic VMA and MH. Release of VMA at day 28 was achieved by $26.5 \%$ of patients in the ocriplasmin group versus $10.1 \%$ in the placebo group $(P<0.001)$. Interestingly, for MHs, the numbers were more remarkable. Predictive factors for successful ocriplasmin treatment were identified for VMT (VMA diameter smaller than 1,500 $\mu \mathrm{m}$ ) and $\mathrm{MH}$ (smaller than $250 \mu \mathrm{m}$ ). In comparison with the highly predictable outcome after vitrectomy, the general success rate of ocriplasmin not under clinical trial conditions has not fully met expectations and needs to be proven in real-world clinical settings. The ocriplasmin data will be compared in the future with observational data on spontaneous VMA release, will help retina specialists make more accurate predictions, and will improve outcome rates.

Keywords: ocriplasmin, microplasmin, posterior vitreous detachment, vitreomacular traction, macular hole, pharmacologic vitreolysis

\section{Introduction}

The vitreoretinal interface consists of an adhesive interaction between matrix proteins such as laminin and fibronectin; these proteins act as a kind of glue, attaching the collagen fibrils of the posterior vitreous cortex to the internal limiting membrane (ILM). ${ }^{1,2}$ In its innocuous form, posterior vitreous detachment (PVD) is an age-related physiologic change in which the posterior hyaloid progressively and completely separates from the retinal surface. ${ }^{3}$ Anomalous PVD (APVD) is thought to occur when vitreoretinal adherence and traction are exerted at this interface without concomitant release of the posterior hyaloid. ${ }^{4}$ The remaining vitreomacular adhesion (VMA) may be asymptomatic, or it may lead to visual changes if there is an associated vitreomacular traction (VMT) or macular hole $(\mathrm{MH}) .^{5}$ The anteroposterior vitreous dynamics of an APVD are associated with types of age-related macular degeneration (AMD) and diabetic macular edema (DME). ${ }^{6-8}$ 
In cases of a focal or a broad VMT, there is a persistent macular attachment of the full-thickness, unsplit posterior vitreous cortex to the macula with perifoveal PVD. ${ }^{3}$

Optical coherence tomography (OCT) has improved significantly our understanding of the vitreomacular interface. OCT-based interpretation of VMT includes anatomical alterations such as pseudocysts, cystoid macular edema, epiretinal membrane (ERM), and macular schisis. ${ }^{5,9}$ The International Vitreomacular Traction Study Group recently proposed a classification system for VMA, VMT, and MH. ${ }^{5}$ According to this system, VMA refers to the stage in which there is perifoveal vitreous detachment with foveal vitreous adherence $(3 \mathrm{~mm}$ radius) and no detectable change in the retinal morphology. VMT represents the stage in which distortion of the foveal surface, intraretinal structural changes, and/or elevation of the fovea occurs in association with macular attachment of the vitreous, as described for VMA. ${ }^{5}$ Autopsy studies of human eyes using scanning electron microscopy have demonstrated that PVD is associated with vitreous cortex remnants at the fovea in $44 \%$ of eyes. ${ }^{10}$ When these remnants are a layer or sheet of posterior vitreous cortex, the term vitreoschisis is appropriate. The tangential contraction of this layer is associated with macular pucker and $\mathrm{MH}$ formation. ${ }^{11,12}$

The standard treatment for VMT and MH is a three-port pars plana vitrectomy. Because of the risks and the complexity of vitrectomy versus an injection, surgery is usually delayed until a significant visual impairment is detected. ${ }^{13}$ Intravitreous injection of vitreolytic compounds (so-called pharmacologic vitreolysis) has been studied as an alterna- tive treatment, aiming to cause vitreous liquefaction and a complete posterior vitreous separation from the retina, as in a PVD. Recently, ocriplasmin, a vitreolytic agent previously known as microplasmin, was demonstrated to be effective and safe, and its use has been approved by the US Food and Drug Administration. ${ }^{13,14}$

In this review, we summarize the outcomes of clinical trials that studied the safety and efficacy of intravitreal ocriplasmin for the management of symptomatic VMA in specific situations. We also review the initial results of its use in clinical practice. In addition, it is relevant to address the expectations for ocriplasmin and pharmacologic vitreolysis in the future, as well as their possible eventual benefits in the treatment of pathologies related to VMA.

\section{Methods}

Between July and October 2013, we conducted literature searches in MEDLINE, using PubMed, and in the Cochrane Library, with no date restrictions. The search strategy used the following words: ocriplasmin, microplasmin, posterior vitreous detachment, vitreomacular adhesion, VMA, vitreomacular traction, VMT, macular hole, vitreolysis, pharmacologic vitreolysis, vitreomacular interface, epiretinal membrane, diabetic macular edema, diabetic retinopathy, AMD, and age-related macular degeneration.

\section{Results and discussion}

Posterior vitreous detachment is a generally benign physiologic event (Figure 1). However, after perifoveal detachment,
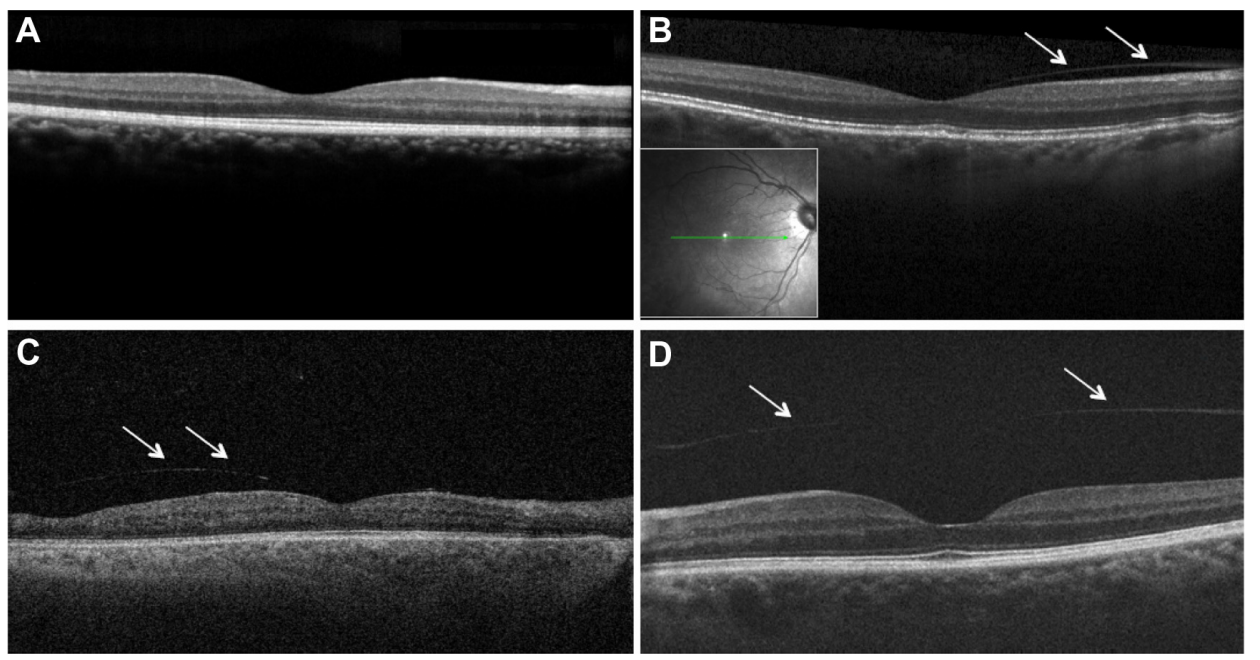

Figure I Images of macular region on spectral domain and swept source optical-coherence tomography (A, B, D: Spectralis OCT, Heidelberg Engeneering, Heidelberg, Germany; C: SS OCT; CArl Zeiss, Oberkochen, Germany).

Notes: (A) Attached posterior hyaloid. (B and C) Partial elevation of the nasal posterior vitreous (partial posterior vitreous detachment) can be seen as a thin layer (arrows) anterior of the retinal surface. Vitreous is still attached in foveal region. (D) Complete vitreous detachment, an entire separation between the posterior vitreous cortex (arrows) and the retina surface. 
the hyaloid remains attached to the macula as a foveolar bond. In the case of abnormal vitreomacular adhesion, pathologic macular stress may arise from two different traction forces: static, in which the hyaloid applies an anteriorly directed vector force to the fovea, and dynamic, which is related to vitreous movements during ocular saccades and is more relevant than static force. ${ }^{3}$ Kishi et $\mathrm{al}^{10}$ observed residual vitreous in the retinal surface in $44 \%$ of autopsy eyes that supposedly had PVD. Later, Johnson ${ }^{3}$ observed that in eyes with focal vitreomacular adhesion with a diameter less than $500 \mu \mathrm{m}$, a higher traction force per unit area leads more commonly to focal macular pathologies such as $\mathrm{MH}$ (full-thickness or inner lamellar hole) and VMT (Figure 2), whereas VMA with a larger diameter (around $1,500 \mu \mathrm{m}$ ) tends to cause more diffuse changes, characterized by macular thickening or stretching, such as ERM.

The typical management of asymptomatic VMA and VMT involves observation. Watchful waiting may be the choice for handling symptomatic cases, as spontaneous separation can occur; otherwise, the standard interventional approach is to surgically release the traction. There is little evidence regarding the consequences and benefits of observing symptomatic VMA. In one study conducted before OCT was clinically available, Hikichi et $\mathrm{al}^{15}$ found that only $11 \%$ of their 53 patients developed complete PVD during the 60 months of follow-up. The natural course of VMA was studied by John et $\mathrm{al}^{16}$ in 2012; their results showed that of 106 symptomatic eyes followed-up for 23 months, 32\% experienced spontaneous release of the adhesion. Other studies indicated that although VMT may resolve spontaneously, the time for resolution might be lengthy, leading to a progressive loss of vision even after a successful intervention. ${ }^{17-19}$

In eyes with full-thickness $\mathrm{MH}(\mathrm{FTMH})$, the evidence indicates more clearly whether treatment is necessary. Kim et $\mathrm{al}^{20}$ demonstrated that approximately $75 \%$ of stage $2 \mathrm{MH}$ cases progress to stage 3 or 4 . Although Ezra ${ }^{21}$ indicated that $30 \%$ to $50 \%$ of stage $1 \mathrm{MH}$ cases tend to close spontaneously, the closure rate was $94 \%$ in $\mathrm{MH}$ present for less than a year versus $47 \%$ in those present for more than a year, according to Jaycock et al. ${ }^{22}$ Extended observation, however, is unreasonable, as the longer the $\mathrm{MH}$ is present, the lower the chance of a successful surgical result, according to Ryan and Gilbert. ${ }^{23}$ Pars plana vitrectomy with ILM removal is the standard surgical treatment for $\mathrm{MH}$, and not only OCT but also ultrasonography may be useful for following and indicating surgical intervention in such eyes. ${ }^{24,25}$

\section{Pharmacologic vitreolysis}

The objective of pharmacologic vitreolysis is to promote a posterior vitreous detachment by releasing the adhesion between the vitreous and the internal limiting membrane. ${ }^{26-28}$ It may be used in conjunction with vitrectomy or as a standalone therapy. ${ }^{29}$

Pharmacology-assisted vitrectomy aims for vitreous liquefaction and weaker vitreoretinal adhesion, allowing for a faster and easier vitreous removal. ${ }^{29-34}$ It translates into a shorter surgical time; a more efficient, smaller-gauge vitrectomy; and a lower aspiration rate, thereby reducing the risk for iatrogenic tears. ${ }^{29,32,35-38}$ In theory, it also facilitates vitreoretinal cleavage, avoiding vitreous remnants and postoperative complications. ${ }^{29,39,40}$ The safety of the surgical procedure is improved if the chromovitrectomy technique is performed, as it enhances identification and removal of the posterior hyaloid, epiretinal membrane, and ILM. ${ }^{41}$

Vitreolytic agents can also be employed as a definitive treatment for active VMA-related diseases, such as earlystage MH, VMT, and tractional cystoid macular edema. ${ }^{4,29,42,43}$ The use of pharmacologic vitreolysis can also benefit conditions in which PVD is associated with an improved prognosis, such as DME ${ }^{8}$ proliferative diabetic retinopathy, ${ }^{44}$ retinal vein occlusion, ${ }^{45-47}$ and AMD. ${ }^{6,729}$ In these cases, complete PVD is related to better anatomical and functional outcomes while reducing the incidence of progressive disease requiring surgery. ${ }^{29,36,38}$
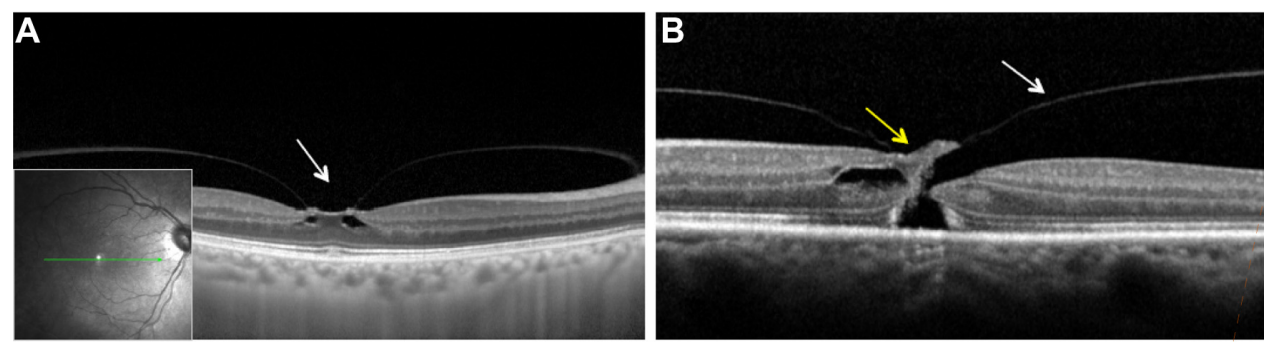

Figure 2 Images of macular region on spectral domain optical coherence tomography (SD-OCT; Spectralis OCT, Heidelberg Engeneering, Heidelberg, Germany). Notes: (A) Vitreomacular traction with focal traction at foveal (arrow) region and intrafoveal pseudocysts. (B) Full-thickness macular hole with vitreomacular traction (yellow and white arrows, respectively). 
The mechanism of PVD is not yet fully understood, but over the last 2 decades, many studies have contributed to a better comprehension of the molecular organization, structure, and physiology of the vitreous, promoting the development of pharmacologic vitreolytics. ${ }^{28,29,31}$ The connection between cortical vitreous collagen with the ILM surface is believed to be mediated by some form of extracellular matrix "glue," including the proteins laminin and fibronectin. ${ }^{1,28,29,48-50}$ Because of its ability to specifically cleave laminin and fibronectin, plasmin has been thoroughly studied in the induction of PVD. ${ }^{28}$ In vitro models and animal studies have shown that intravitreal injection of plasmin alone or injection followed by vitrectomy was sufficient to produce a clean separation between the vitreous cortex and the retina and that this was directly influenced by plasmin concentration and length of exposure. ${ }^{28,49,51-54}$ Uemura et al ${ }^{50}$ showed that intravitreous injection of plasmin dramatically decreased the density of fibronectin and laminin, reducing the molecules to several fragments of lower molecular weights at the ILM.

Apart from the cleavage of fibronectin and laminin, plasmin has an additional ability to activate endogenous matrix metalloproteinases (MMPs); namely, MMP-2 (gelatinase A), which is normally found in the vitreous. MMP-2 has an affinity for various collagens, including basement membrane type IV, and it is thought to play an important role in vitreous liquefaction. ${ }^{28,55-57}$ This may facilitate vitreous removal, as corroborated by some studies. ${ }^{37}$ For instance, Hermel et $\mathrm{a}^{37}$ described a $27 \%$ increase in vitreous removal through a 25-gauge vitrectomy system in rabbit eyes injected with plasmin when compared with no preoperative injection.

In humans, autologous intravitreous plasmin has been used as an adjunct therapy to vitrectomy in a number of clinical studies. In cases of tractional DME, preoperative injection of plasmin promoted higher incidences of spontaneous PVD at the time of surgery and required lower aspiration rates to induce PVD when needed, leading to better visual outcomes when compared with controls..$^{39,58,59}$ Another study of patients with proliferative diabetic retinopathy achieved a significant reduction in surgical time and showed a decreased risk for iatrogenic retinal breaks. ${ }^{60}$ Successful anatomic outcomes were also described in pediatric patients with stage 5 retinopathy of prematurity, traumatic $\mathrm{MH}$, and complex X-linked retinoschisis cases. ${ }^{61-63}$ In the treatment of stage 3 FTMH, the use of plasmin induced a higher rate of spontaneous intraoperative PVD and reduced total surgical time..$^{33,50,64,65}$

Autologous plasmin, in contrast, presents important limitations that compromise its routine clinical use. Although it might be harvested from the patient's blood, the production process is usually expensive and time-consuming. Because the compound is unstable and can be inactivated via autolysis within a short period of time, it must be prepared immediately before surgery. ${ }^{28}$

To overcome these shortcomings while sustaining the benefits of autologous plasmin, a new recombinant compound, ocriplasmin, was developed. ${ }^{66,67}$ Ocriplasmin (Jetrea ${ }^{\circledR}$; ThromboGenics NV, Leuven, Belgium) has been evaluated in several preclinical studies and clinical trials described herein.

\section{Ocriplasmin}

Ocriplasmin, formerly known as microplasmin, was recently approved for the management of symptomatic VMA in the European Union and in the United States. ${ }^{14,68}$ This bioengineered, recombinant, stable, truncated form of plasmin, a human serine protease, consists of only the catalytic domain from plasmin but has practically the same functional proteolytic activity against fibronectin and laminin. ${ }^{66,67,69}$ Ocriplasmin has several advantages over plasmin; most notably, ocriplasmin is considerably more stable than plasmin. Ocriplasmin is also smaller than plasmin $(27 \mathrm{KDa}$ versus $83 \mathrm{KDa}$ ), supposedly resulting in increased penetration of the tissues. In addition, ocriplasmin is generated by recombinant techniques, which ensures its sterility. $29,67,68$

Ocriplasmin may induce vitreous liquefaction and vitreoretinal separation. Several preclinical studies investigated its pharmacodynamic properties after intravitreal injection. Gandorfer et $\mathrm{al}^{70}$ initially reported that ocriplasmin resulted in a time- and dose-dependent induction of PVD in felines without adverse effects. These researchers showed the same results in cadaveric eyes, injecting 125 or $188 \mu \mathrm{g}$ intravitreously; complete PVD was induced after 30 minutes, leaving an essentially smooth and clean ILM. Later, Sakuma et al, ${ }^{71}$ using rabbit eyes, and De Smet et $\mathrm{al},{ }^{72}$ using porcine eyes, demonstrated the same satisfactory outcomes of safety and complete induction of PVD. The minimal effective dose appeared to be $125 \mu \mathrm{g}$.

Intravitreal ocriplasmin pharmacokinetics was studied in a nonrandomized Phase II trial, the Microplasmin Intravitreal Injection (MIVI)-10. A single injection of $125 \mu \mathrm{g}$ ocriplasmin was given before pars plana vitrectomy. ${ }^{73}$ Thirty-eight eyes were enrolled, receiving the treatment at different times before surgery: group 1, 5-30 minutes; group 2, 31-60 minutes; group 3, 2-4 hours; group 4, 24 hours; and group 5, 7 days. Participants in group 6 (control) did not receive the ocriplasmin injection. Mean ocriplasmin activity levels in the vitreous were measured, and the results were as follows: group 1, $12 \mu \mathrm{g} / \mathrm{mL}$; group 2, $8.1 \mu \mathrm{g} / \mathrm{mL}$; group 3, 
$2.6 \mu \mathrm{g} / \mathrm{mL}$; group 4, $0.49 \mu \mathrm{g} / \mathrm{mL}$; and group 5, less than $0.272 \mu \mathrm{g} / \mathrm{mL}$, similar to the control group.

\section{Clinical trials and recent results}

The MIVI trials, sponsored by ThromboGenics, were a series of clinical trials conducted to investigate the effect of microplasmin in humans. The Phase II MIVI-10 study cited earlier is a part of these trials.

MIVI-I, a Phase I/IIa study, as well as MIVI-IIT and MIVI-III, two randomized controlled Phase II clinical trials, evaluated dose response along with the safety and effectiveness of ocriplasmin. The $125 \mu \mathrm{g}$ dose was considered safe and was associated with optimal efficacy, as patients receiving $125 \mu \mathrm{g}$ of ocriplasmin were more likely to present PVD than controls. The results from MIVI-IIT and MIVI-III indicated the potential of ocriplasmin as a nonsurgical alternative for the treatment of VMT. $26,35,74$

These encouraging results from Phase II trials increased expectations regarding a Phase III study. The MIVI-TRUST program (Microplasmin for Intravitreal Injection - Traction Release Without Surgical Treatment) consists of two Phase III clinical trials evaluating ocriplasmin for the treatment of symptomatic VMA. MIVI-006, conducted in the United States, and MIVI-007, conducted in both the United States and Europe, were practically identical multicenter, randomized, double-masked, placebo-controlled studies designed to test the efficacy and safety of a single dose of $125 \mu \mathrm{g}$ ocriplasmin injected intravitreously. ${ }^{13}$ ThromboGenics sponsored, coordinated, and designed both studies.

The inclusion criteria were diagnosis of symptomatic focal VMA seen on OCT and confirmed by a central reading center and a best-corrected visual acuity (BCVA) of 20/25 or worse. It is noteworthy that including patients with good visual acuity might lead to a ceiling effect, meaning that fewer patients had visual acuity poor enough to have a more significant gain. Exclusion criteria included high myopia, prior vitrectomy, prior macular photocoagulation, $\mathrm{MH}$ greater than $400 \mu \mathrm{m}$, and other retinal pathologies that could affect visual function. Patients with ERM were not excluded. ${ }^{13}$

In total, 652 patients were enrolled: 464 patients were randomly assigned to receive a $0.10 \mathrm{~mL}$ intravitreal injection of a solution containing $125 \mu \mathrm{g}$ ocriplasmin and 188 patients were randomly assigned to receive a $0.10 \mathrm{~mL}$ intravitreal injection of a placebo solution containing the identical drug vehicle diluted with saline. The primary endpoint was nonsurgical VMA resolution at day 28 , as determined by OCT at a formal reading center. The main secondary endpoint was total posterior vitreous detachment at day 28 , as determined by standardized B-scan ultrasonograms performed by the investigator. Nonsurgical closure of FTMH, BCVA improvement of three lines or more, change from baseline in BCVA, need for vitrectomy, and visual function questionnaire assessment at 6 months were also considered secondary endpoints. ${ }^{13}$

Considering data from both trials, the primary endpoint of pharmacologic VMA release was achieved in $26.5 \%$ of patients in the ocriplasmin group versus $10.1 \%$ of patients in the placebo group $(P<0.001)$. The VMA resolution rate was higher when VMA diameter was $1,500 \mu \mathrm{m}$ or less (37.4\% versus [vs] $14.6 \% ; P<0.001)$ than in those with VMA diameter greater than $1,500 \mu \mathrm{m}$. In patients with ERM, ocriplasmin injection did not have such positive results $(8.7 \%$ vs $1.5 \% ; P<0.046)$ compared with VMA without ERM $(37.4 \%$ vs $14.3 \% ; P<0.001)$. In those patients with pure VMT at baseline, without ERM or MH, there was a success rate of $29.8 \%$ in the group treated with ocriplasmin versus $7.7 \%$ in the placebo. Considering FTMH, the closure rate in the ocriplasmin group was of $40.6 \%$ at day 28 and remained as high at the end of the study at 6 months, whereas the placebo group had a $10.6 \%(P<0.001)$ closure rate at day 28 and $17 \%$ at 6 months $(P=0.004)$. Closure rates varied according to the FTMH width at baseline. ${ }^{13,67}$

Regarding improvement of the BCVA, the outcomes were also positive in favor of ocriplasmin, although only a modest mean change was shown, likely because of the previously mentioned ceiling effect. The PVD rate was significantly higher in the ocriplasmin group as well. Patients with ERM and VMA greater than $1,500 \mu \mathrm{m}$ in diameter did not appear to benefit from ocriplasmin injection. Regarding the safety profile, ocriplasmin had a higher rate of ocular adverse effects. Vitreous floaters, photopsia, and conjunctival hemorrhage occurred in $68.4 \%$ of the ocriplasmin group compared with $53.5 \%$ of the placebo group, a statistically significant difference $(P<0.001)$, with many of them related to VMA release and PVD. Blurred vision, mostly transient, occurred more in the ocriplasmin group, which might be a result of the worsening of VMT before release of VMA. The incidence of serious ocular adverse events such as retinal tear or retinal detachment was similar in the two groups $(P=0.11) .{ }^{13}$

Summarizing the outcomes from the Phase III trials, a single injection of $125 \mu \mathrm{g}$ ocriplasmin was shown to be safe and to significantly increase the rates of VMA resolution and FTMH closure when compared with placebo. However, the magnitude of clinical benefit was lower than expected, considering that this is an expensive and invasive procedure, as only approximately one-quarter of the included patients achieved the primary endpoint. In contrast, it is relevant to note that the success rate appears higher for focal VMA less than $1,500 \mu \mathrm{m}$ in diameter and small $\mathrm{MH}$ 
A post hoc subgroup analysis suggested that FTMH smaller than $250 \mu \mathrm{m}$ had higher closure rates compared with $\mathrm{MH}$ between 250 and $400 \mu \mathrm{m}$ (58\% vs 37\%; unpublished data, ThromboGenics [2013]). Not only is the absence of ERM an important indicator of success, but its presence is a predictor of failure of treatment with ocriplasmin. In this regard, the ongoing trial Ocriplasmin for Treatment of Symptomatic Vitreomacular Adhesion Including Macular Hole (OASIS) intends to assess whether a more specific case selection can increase the success rates. ${ }^{13,75,76}$

A relevant drawback of this Phase III study was the use of time-domain OCT, whereas spectral-domain OCT was used only when available. The presence or absence of ERM was earlier shown to be significant for success of treatment with ocriplasmin. Hence, if spectral-domain OCT had been used exclusively, the results might be different, as the assessment of ERM is more profound with spectral-domain OCT. ${ }^{77}$

It is important to consider that data from a controlled clinical trial evaluating a premarket drug profile may be significantly different from the results that would be observed in clinical practice. For example, in the Phase III studies, the ocriplasmin group was superior to placebo with regard to having complete PVD at day 28. These results were confirmed by B-scan ultrasonograms, and investigators were trained in and followed a strict protocol to obtain reliable, standardized data. Such a protocol is unsuitable for a real-world setting; therefore, the complete PVD rate might be substantially different than the trial outcomes.

Kim et $\mathrm{al}^{78}$ recently published their initial outcomes on the use of intravitreal ocriplasmin in clinical practice. In a retrospective review of 19 patients with symptomatic VMA treated with ocriplasmin, they found a resolution of the VMA in $42.1 \%$ of nonsurgical cases. Patients with ERM at baseline had a lower success rate of VMA resolution (25\%) than patients without baseline ERM (45.5\%), which is comparable to what was observed in the clinical trials. The evident limitations of this study do not allow additional conclusions related to the efficacy and safety of ocriplasmin. However, these initial results are encouraging and meet the expectations. Data from clinical experience provide the real profile of ocriplasmin for the treatment of symptomatic VMA, and such data will determine how beneficial this agent is in daily practice.

Conversely, since ocriplasmin has been available for practical use, safety concerns have been raised from reports on visual disturbances after intravitreal injection of the drug. Transient profound vision loss and darkening of vision were recently observed in patients treated with ocriplasmin. ${ }^{98}$ Such relevant adverse events, added to the potential of lens subluxation, dyschromatopsia and other unfavorable events observed in the clinical trial, should arouse the attention of ophthalmologists. ${ }^{99}$

Retinal detachment and retinal tear did not appear to be a concerning factor with regard to ocriplasmin injection, not only in this retrospective review but also in clinical trials. The rate of retinal detachment was not statistically different between ocriplasmin and placebo in the MIVI-TRUST. Considering that ocriplasmin may induce acute PVD, patients with high myopia and lattice degeneration with atrophic holes could be at higher risk for a retinal tear or detachment. Although there is no evidence up to now of a higher risk for retinal detachment after injection of ocriplasmin, this relevant implication of enzymatic vitreolysis needs to be clarified in future studies, as the (controversial) role of prophylactic laser in selected cases may change.

\section{Ocriplasmin: boundaries and future}

Positive results from trials have made ocriplasmin a promising pharmacologic agent for the treatment of symptomatic VMA. Its indication, however, is limited to selected specific cases. Ongoing studies and investigations that should be launched soon will certainly help improve those results by specifying the indications, and perhaps broadening them as well. Also, safety issues should be clarified in further investigations.

The cost of treatment represents a significant barrier for ocriplasmin to become the standard of care for VMT in the future. The UK National Institute for Health and Care Excellence (NICE) considered its use for treating VMT without ERM to be cost-effective relative to the "wait and watch" option. Nevertheless, it is noteworthy that results derived from the clinical trial indicated that less than one-third of cases achieved VMT release after ocriplasmin injection. Considering that it is an expensive treatment, ocriplasmin should also be compared with vitrectomy with regard to cost-effectiveness. ${ }^{79}$

As a new approach, this agent has the potential for expanded use and benefits. Considering its ability to induce PVD, other ophthalmic conditions and pathologies related to VMA might benefit from ocriplasmin intravitreal injection.

\section{Vitreoretinal surgery}

Complete posterior hyaloid removal from the retinal surface during vitreoretinal surgery is sometimes a challenging procedure, as in cases with tractional retinal detachment secondary to proliferative diabetic retinopathy, for example. Likewise, vitreoretinal adhesion is stronger in patients aged 9 months to 20 years than in those aged 21 years or older, according to Sebag, ${ }^{80}$ thus making surgical hyaloid detachment more difficult in patients younger than 21 years. Whether ocriplasmin 
would be useful as an adjuvant to vitrectomy in these cases is a matter to be clarified. In retinopathy of prematurity and other advanced pediatric vitreoretinopathies in particular, surgical success depends on the complete removal of the vitreous and remaining epiretinal membranes. Wong and Capone ${ }^{81}$ recently reviewed the current evidence supporting the potential role of ocriplasmin as an adjuvant for these cases. They assessed studies on autologous plasmin enzyme as adjunct to vitrectomy for retinopathy of prematurity, in which the reattachment rates were higher when autologous plamin enzime-assisted vitrectomy was performed..$^{62,82}$ In light of the positive results from clinical trials on symptomatic VMA, these results increased expectations with respect to ocriplasmin as an adjuvant and its effect on pediatric vitreoretinal surgical treatment, given its advantages over plasmin. ${ }^{81}$

A Phase II, randomized, placebo-controlled clinical trial of intravitreal ocriplasmin in infants and children up to 16 years of age is ongoing in a single center in the United States. Twenty-four patients who were scheduled for vitrectomy were enrolled to receive either $175 \mu \mathrm{g}$ of ocriplasmin or placebo intravitreal injection 30-60 minutes before their surgical procedures. There are no published results of this efficacy/safety study to date. ${ }^{83}$

\section{DME}

Clinical studies have implicated abnormal VMA as a contributory factor for DME, and eyes with DME were found less likely to have PVD. ${ }^{8,84}$ Laidlaw's ${ }^{85}$ review on this subject found that although most studies indicate that PVD is associated with a reduction of central macular thickness and improvement of vision, other relevant studies found no such benefits. A systematic review and meta-analysis recently concluded that there is no sufficient evidence to assess the prevalence of VMA in DME. ${ }^{86}$ Although no benefit of PVD has been proven in DME, vitreomacular adhesion with VMT could worsen the edema, sustain it, and/or reduce treatment success. ${ }^{86}$

The MIVI-II, another study sponsored by ThromboGenics, is a multicenter, randomized, double-masked, sham-injection controlled clinical trial started in 2006 to investigate PVD induction after intravitreal injection of ocriplasmin in patients with DME. Doses of 25, 75, and $125 \mu \mathrm{g}$ ocriplasmin were compared with sham injection. Fifty-one patients were enrolled, and data collection was completed in 2010. Although no definite results have been published yet, the outcomes provided to date are not encouraging. ${ }^{87}$

\section{AMD}

AMD has also been related to VMA. In 1996, using B-scan ultrasound tomography, Weber-Krause and Eckardt ${ }^{88}$ reported that a posterior vitreous detachment is very rare in eyes with AMD. More recently, Ondes et al have shown that a spontaneous detachment of the vitreous resulted in the natural regression of choroidal neovascularization. ${ }^{88,89}$ Their data demonstrate that only one-third of patients with either wet or dry AMD have a complete PVD compared with half of the patients in a control group. Several other authors have confirmed that a partial or total vitreous adhesion to the retina is associated with a higher risk of AMD, wet and atrophic. 6,7,89-93

In 2007, Krebs et $\mathrm{al}^{6}$ assessed the posterior vitreous with B-scan ultrasonography and OCT to examine the status of 163 eyes in patients with wet AMD, dry AMD, or controls. A PVD was present in only $31 \%$ (17/54) of eyes with wet AMD compared with $72 \%$ (41/57) of eyes with dry AMD and $61 \%(34 / 56)$ of controls. In addition, OCT revealed VMA in $36 \%(18 / 50)$ of eyes with wet AMD, which was significantly higher than in eyes with dry AMD $(7 \%, 4 / 57)$ and control $(11 \%, 6 / 56)$ eyes. ${ }^{6}$ Mojana et $\mathrm{al}^{92}$ used spectral-domain OCT, combined with simultaneous scanning laser ophthalmoscopy, to examine the vitreomacular interface in wet and dry AMD. They found a higher rate of VMA in patients with wet AMD compared with a control group (28\% vs $16 \%)$. Importantly, they also observed that patients with combined wet AMD and VMA had higher rates of VMT (59\%) compared with the dry AMD/VMA (13\%) and control/VMA (12\%) groups.

Recent observational studies have confirmed the general relationship of attached vitreous and microtraction on the retinal surface, which might confound a decreased retinal perfusion in consequence. It may also be possible that local inflammatory reactions in the pathophysiology of AMD might strengthen the adhesion between the ILM and the posterior vitreous membrane, leading to increased rates of VMA in wet AMD. ${ }^{94,95}$ Although none of these reports is fully conclusive, VMA seems to be associated with a higher risk for development or progression of choroidal neovascularization. .,7,90,92 $^{-10}$

A multicenter, randomized, double-masked, shaminjection controlled Phase II study was conducted to assess the safety and efficacy of intravitreal ocriplasmin for the treatment of focal VMA in patients with AMD. The MIVI-5 trial, also sponsored by ThromboGenics, included subjects with exudative AMD who received at least three and no more than nine antiangiogenic intravitreal injections and had focal VMA confirmed on OCT. Primary outcome was the proportion of subjects with focal VMA resolution by day 28. Secondary endpoints included BCVA, mean change of macular thickness, size, fluorescein leakage, and number of anti-VEGF injections required during study. One hun- 
dred patients were randomized to receive either intravitreal injection of $125 \mu \mathrm{g}$ ocriplasmin or sham injection. Although a greater proportion of patients had VMA resolution at day $28(24.3 \%)$ and primary outcome was met in only $12.0 \%$ of eyes in the sham group, the difference was not statistically significant $(P=0.262)$. Nor was the difference between groups significant for secondary endpoints. This study demonstrated no additional benefit of ocriplasmin for the treatment of VMA in patients with exudative AMD. ${ }^{96,97}$

\section{Conclusion}

Pharmacologic vitreolysis has been studied in recent years as an alternative or as an adjuvant to vitrectomy. Ocriplasmin became a promising agent because of its ability to induce PVD by lysing fibronectin, laminin, and other components of the vitreoretinal interface and, ultimately, to its more stable structure compared with plasmin. Recently, Phase III clinical trials demonstrated the efficacy and the safety of ocriplasmin for the management of symptomatic VMA. Real-world settings are considerably different from standards that are set in clinical trials, which used combined ultrasound and OCT examinations. On clinical examination for instance, the inner wall of a vitreoschisis may be clinically confused with a PVD, when the posterior layer of the split vitreous cortex remains attached to the ILM. The therapeutic success rate has thus not fully met expectations, especially considering the high cost of treatment.

Future studies, as well as upcoming results from using ocriplasmin in clinical practice, should provide data that will help clarify the indications and improve outcomes. Further investigations should also address safety concerns. Regarding pathologies such as DME and AMD, it is imperative that the use of an intraocular enzyme is safe and beneficial, as well as affordable for patients.

\section{Acknowledgment}

Susan Clarke performed English editing of the manuscript.

\section{Disclosure}

The authors report no conflicts of interest in this work.

\section{References}

1. Sebag J. Molecular biology of pharmacologic vitreolysis. Trans Am Ophthalmol Soc. 2005;103:473-494.

2. Matsumoto B, Blanks JC, Ryan SJ. Topographic variations in the rabbit and primate internal limiting membrane. Invest Ophthalmol Vis Sci. 1984;25(1):71-82.

3. Johnson MW. Posterior vitreous detachment: evolution and role in macular disease. Retina. 2012;32 Suppl 2:S174-S178.

4. Sebag J. Anomalous posterior vitreous detachment: a unifying concept in vitreo-retinal disease. Graefes Arch Clin Exp Ophthalmol. 2004;242(8): 690-698.
5. Duker JS, Kaiser PK, Binder S, et al. The International Vitreomacular Traction Study Group classification of vitreomacular adhesion, traction, and macular hole. Ophthalmology. 2013;120(12):2611-2619.

6. Krebs I, Brannath W, Glittenberg C, Zeiler F, Sebag J, Binder S. Posterior vitreomacular adhesion: a potential risk factor for exudative age-related macular degeneration? American journal of ophthalmology. 2007;144(5):741-746.

7. Lee SJ, Lee CS, Koh HJ. Posterior vitreomacular adhesion and risk of exudative age-related macular degeneration: paired eye study. $\mathrm{Am} \mathrm{J}$ Ophthalmol. 2009;147(4):621-626.

8. Nasrallah FP, Jalkh AE, Van Coppenolle F, et al. The role of the vitreous in diabetic macular edema. Ophthalmology. 1988;95(10):1335-1339.

9. Stalmans P, Duker JS, Kaiser PK, et al. Oct-based interpretation of the vitreomacular interface and indications for pharmacologic vitreolysis. Retina. 2013;33(10):2003-2011.

10. Kishi S, Demaria C, Shimizu K. Vitreous cortex remnants at the fovea after spontaneous vitreous detachment. Int Ophthalmol. 1986;9(4): 253-260.

11. Gupta P, Sadun AA, Sebag J. Multifocal retinal contraction in macular pucker analyzed by combined optical coherence tomography/scanning laser ophthalmoscopy. Retina. 2008;28(3):447-452.

12. Gupta P, Yee KM, Garcia P, et al. Vitreoschisis in macular diseases. Br J Ophthalmol. 2011;95(3):376-380.

13. Stalmans P, Benz MS, Gandorfer A, et al; MIVI-TRUST Study Group. Enzymatic vitreolysis with ocriplasmin for vitreomacular traction and macular holes. $N$ Engl J Med. 2012;367(7):606-615.

14. FDA approves Jetrea for symptomatic vitreomacular adhesion in the eyes. US Food and Drug Adminsitration; 2012 [updated October 18, 2012; cited October 23, 2013]. Available from: http://www.fda.gov/ NewsEvents/Newsroom/PressAnnouncements/ucm324369.htm. Accessed October 23, 2013.

15. Hikichi T, Yoshida A, Akiba J, Trempe CL. Natural outcomes of stage 1, 2, 3, and 4 idiopathic macular holes. Br J Ophthalmol. 1995;79(6): 517-520.

16. John VJ, Flynn HW Jr, Smiddy WE, et al. Clinical course of vitreomacular adhesion managed by initial observation. Retina. 2014 March;34(3):442-446.

17. Sonmez K, Capone A Jr, Trese MT, Williams GA. Vitreomacular traction syndrome: impact of anatomical configuration on anatomical and visual outcomes. Retina. 2008;28(9):1207-1214.

18. Melberg NS, Williams DF, Balles MW, et al. Vitrectomy for vitreomacular traction syndrome with macular detachment. Retina. 1995;15(3):192-197.

19. Bottós JM, Elizalde J, Rodrigues EB, Maia M. Current concepts in vitreomacular traction syndrome. Curr Opin Ophthalmol. 2012;23(3): 195-201.

20. Kim JW, Freeman WR, Azen SP, el-Haig W, Klein DJ, Bailey IL. Prospective randomized trial of vitrectomy or observation for stage 2 macular holes. Vitrectomy for Macular Hole Study Group. Am J Ophthalmol. 1996;121(6):605-614.

21. Ezra E. Idiopathic full thickness macular hole: natural history and pathogenesis. Br J Ophthalmol. 2001;85(1):102-108.

22. Jaycock PD, Bunce C, Xing W, et al. Outcomes of macular hole surgery: implications for surgical management and clinical governance. Eye (Lond). 2005;19(8):879-884.

23. Ryan EH Jr, Gilbert HD. Results of surgical treatment of recentonset full-thickness idiopathic macular holes. Arch Ophthalmol. 1994;112(12):1545-1553.

24. Bainbridge J, Herbert E, Gregor Z. Macular holes: vitreoretinal relationships and surgical approaches. Eye (Lond). 2008;22(10): 1301-1309.

25. Bottós JM, Torres VL, Kanecadan LA, et al. Macular hole: 10 and 20-MHz ultrasound and spectral-domain optical coherence tomography. Arq Bras Oftalmol. 2012;75(6):415-419.

26. de Smet MD, Gandorfer A, Stalmans P, et al. Microplasmin intravitreal administration in patients with vitreomacular traction scheduled for vitrectomy: the MIVI I trial. Ophthalmology. 2009;116(7):1349-1355. 
27. Gandorfer A. Objective of pharmacologic vitreolysis. Dev Ophthalmol. 2009;44:1-6.

28. Tsui I, Pan CK, Rahimy E, Schwartz SD. Ocriplasmin for vitreoretinal diseases. J Biomed Biotechnol. 2012;2012:354979.

29. Schneider EW, Johnson MW. Emerging nonsurgical methods for the treatment of vitreomacular adhesion: a review. Clin Ophthalmol. 2011;5:1151-1165.

30. Gandorfer A. Pharmacologic vitreolysis. Dev Ophthalmol. 2007;39: $149-156$.

31. Gandorfer A. Enzymatic vitreous disruption. Eye (Lond). 2008;22(10): 1273-1277.

32. Gandorfer A, Ulbig M, Kampik A. Plasmin-assisted vitrectomy eliminates cortical vitreous remnants. Eye (Lond). 2002;16(1):95-97.

33. Trese MT. Enzymatic vitreous surgery. Semin Ophthalmol. 2000;15(2): $116-121$

34. Trese MT. Enzymatic-assisted vitrectomy. Eye (Lond). 2002;16(4): 365-368.

35. Benz MS, Packo KH, Gonzalez V, et al. A placebo-controlled trial of microplasmin intravitreous injection to facilitate posterior vitreous detachment before vitrectomy. Ophthalmology. 2010;117(4): 791-797.

36. Bhisitkul RB. Anticipation for enzymatic vitreolysis. Br J Ophthalmol. 2001;85(1):1-2.

37. Hermel M, Prenner J, Alabdulrazzak M, Dailey W, Hartzer M. Effect of intravitreal plasmin on vitreous removal through a 25-gauge cutting system in the rabbit in vivo. Graefes Arch Clin Exp Ophthalmol. 2009;247(3):331-334.

38. Sebag J. Pharmacologic vitreolysis. Retina. 1998;18(1):1-3.

39. Asami T, Terasaki H, Kachi S, et al. Ultrastructure of internal limiting membrane removed during plasmin-assisted vitrectomy from eyes with diabetic macular edema. Ophthalmology. 2004;111(2):231-237.

40. Capeans C, Lorenzo J, Santos L, et al. Comparative study of incomplete posterior vitreous detachment as a risk factor for proliferative vitreoretinopathy Graefes Arch Clin Exp Ophthalmol. 1998;236(7):481-485.

41. Farah ME, Maia M, Rodrigues EB. Dyes in ocular surgery: principles for use in chromovitrectomy. Am J Ophthalmol. 2009;148(3):332-340.

42. Johnson MW. Perifoveal vitreous detachment and its macular complications. Trans Am Ophthalmol Soc. 2005;103:537-567.

43. Johnson MW. Posterior vitreous detachment: evolution and complications of its early stages. Am J Ophthalmol. 2010;149(3):371-382.

44. Akiba J, Arzabe CW, Trempe CL. Posterior vitreous detachment and neovascularization in diabetic retinopathy. Ophthalmology. 1990;97(7): 889-891.

45. Akiba J, Kado M, Kakehashi A, Trempe CL. Role of the vitreous in posterior segment neovascularization in central retinal vein occlusion. Ophthalmic Surg. 1991;22(9):498-502.

46. Avunduk AM, Cetinkaya K, Kapicioğlu Z, Kaya C. The effect of posterior vitreous detachment on the prognosis of branch retinal vein occlusion. Acta Ophthalmol Scand. 1997;75(4):441-442.

47. Hikichi T, Konno S, Trempe CL. Role of the vitreous in central retinal vein occlusion. Retina. 1995;15(1):29-33.

48. Chen W, Mo W, Sun K, Huang X, Zhang YL, Song HY. Microplasmin degrades fibronectin and laminin at vitreoretinal interface and outer retina during enzymatic vitrectomy. Curr Eye Res. 2009;34(12): 1057-1064.

49. Li X, Shi X, Fan J. Posterior vitreous detachment with plasmin in the isolated human eye. Graefes Arch Clin Exp Ophthalmol. 2002;240(1): 56-62.

50. Uemura A, Nakamura M, Kachi S, et al. Effect of plasmin on laminin and fibronectin during plasmin-assisted vitrectomy. Arch Ophthalmol. 2005;123(2):209-213.

51. Gandorfer A, Priglinger S, Schebitz K, et al. Vitreoretinal morphology of plasmin-treated human eyes. Am J Ophthalmol. 2002;133(1): $156-159$.

52. Gandorfer A, Putz E, Welge-Lüssen U, Grüterich M, Ulbig M, Kampik A. Ultrastructure of the vitreoretinal interface following plasmin assisted vitrectomy. Br J Ophthalmol. 2001;85(1):6-10.
53. Hikichi T, Yanagiya N, Kado M, Akiba J, Yoshida A. Posterior vitreous detachment induced by injection of plasmin and sulfur hexafluoride in the rabbit vitreous. Retina. 1999;19(1):55-58.

54. Kim NJ, Yu HG, Yu YS, Chung H. Long-term effect of plasmin on the vitreolysis in rabbit eyes. Korean J Ophthalmol. 2004;18(1):35-40.

55. Brown DJ, Bishop P, Hamdi H, Kenney MC. Cleavage of structural components of mammalian vitreous by endogenous matrix metalloproteinase-2. Curr Eye Res. 1996;15(4):439-445.

56. Gandorfer A, Kampik A. Intravitreal plasmin injection activates endogenous matrix metalloproteinase-2 in rabbit and human vitreous. Am J Ophthalmol. 2006;141(4):784-785.

57. Sivak JM, Fini ME. MMPs in the eye: emerging roles for matrix metalloproteinases in ocular physiology. Prog Retin Eye Res. 2002;21(1): $1-14$.

58. Azzolini C, D’Angelo A, Maestranzi G, et al. Intrasurgical plasmin enzyme in diabetic macular edema. Am J Ophthalmol. 2004;138(4): $560-566$.

59. Sakuma T, Tanaka M, Inoue J, Mizota A, Souri M, Ichinose A. Use of autologous plasmin during vitrectomy for diabetic maculopathy. Eur J Ophthalmol. 2006;16(1):138-140.

60. Hirata A, Takano A, Inomata Y, Yonemura N, Sagara N, Tanihara H. Plasmin-assisted vitrectomy for management of proliferative membrane in proliferative diabetic retinopathy: a pilot study. Retina. 2007;27(8): 1074-1078.

61. Wu WC, Drenser KA, Capone A, Williams GA, Trese MT. Plasmin enzyme-assisted vitreoretinal surgery in congenital X-linked retinoschisis: surgical techniques based on a new classification system. Retina. 2007;27(8):1079-1085.

62. Wu WC, Drenser KA, Lai M, Capone A, Trese MT. Plasmin enzymeassisted vitrectomy for primary and reoperated eyes with stage 5 retinopathy of prematurity. Retina. 2008;28(Suppl 3):S75-S80.

63. Wu WC, Drenser KA, Trese MT, Williams GA, Capone A. Pediatric traumatic macular hole: results of autologous plasmin enzyme-assisted vitrectomy. Am J Ophthalmol. 2007;144(5):668-672.

64. Rizzo S, Pellegrini G, Benocci F, Belting C, Baicchi U, Vispi M. Autologous plasmin for pharmacologic vitreolysis prepared 1 hour before surgery. Retina. 2006;26(7):792-796.

65. Sakuma T, Tanaka M, Inoue M, Mizota A, Souri M, Ichinose A. Efficacy of autologous plasmin for idiopathic macular hole surgery. Eur J Ophthalmol. 2005;15(6):787-794.

66. Gandorfer A. Pharmacologic vitreolysis: rationale, potential indications, and promising agents. Retina. 2012;32 Suppl 2:S221-S224.

67. Syed YY, Dhillon S. Ocriplasmin: a review of its use in patients with symptomatic vitreomacular adhesion. Drugs. 2013;73(14):1617-1625.

68. European Medicines Agency recommends approval of medicine for treatment of vitreomacular traction. European Medicines Agency; 2013 [updated January 18, 2013; cited October 26, 2013]. Available from: http://www.ema.europa.eu/ema/index.jsp?curl=pages/medicines/ human/medicines/002381/smops/Positive/human_smop_000466. jsp\&mid=WC0b01ac058001d127. Accessed October 23, 2013.

69. Wu HL, Shi GY, Bender ML. Preparation and purification of microplasmin. Proc Natl Acad Sci U S A. 1987;84(23):8292-8295.

70. Gandorfer A, Rohleder M, Sethi C, et al. Posterior vitreous detachment induced by microplasmin. Invest Ophthalmol Vis Sci. 2004;45(2): 641-647.

71. Sakuma T, Tanaka M, Mizota A, Inoue J, Pakola S. Safety of in vivo pharmacologic vitreolysis with recombinant microplasmin in rabbit eyes. Invest Ophthalmol Vis Sci. 2005;46(9):3295-3299.

72. de Smet MD, Valmaggia C, Zarranz-Ventura J, Willekens B. Microplasmin: ex vivo characterization of its activity in porcine vitreous. Invest Ophthalmol Vis Sci. 2009;50(2):814-819.

73. Ocriplasmin (Jetreatm) Briefing Document-BLA 125422. US Food and Drug Administration, Dermatologic and Ophthalmic Drugs Advisory Committee; 2012 [cited October 30, 2013]. Available from: http://www. fda.gov/downloads/advisorycommittees/committeesmeetingmaterials/ drugs/dermatologicandophthalmicdrugsadvisorycommittee/ ucm313091.pdf. Accessd October 23, 2013. 
74. Stalmans P, Delaey C, de Smet MD, van Dijkman E, Pakola S. Intravitreal injection of microplasmin for treatment of vitreomacular adhesion: results of a prospective, randomized, sham-controlled phase II trial (the MIVI-IIT trial). Retina. 2010;30(7):1122-1127.

75. Ocriplasmin for Treatment for Symptomatic Vitreomacular Adhesion/ (VMT) Including Macular Hole (OASIS). ClinicalTrials.gov; 2012 [updated November 3, 2013; cited November 4, 2013]. Available from: http://ClinicalTrials.gov/ct2/show/NCT01429441?term=Ocriplasmin\& rank=9. Accessed October 23, 2013.

76. Application number: 125422orig1s000 medical review. US Food and Drug Administration, Center for Drug Evaluation and Research; 2012 [cited November 6, 2013]. Available from: http://www.accessdata.fda. gov/drugsatfda_docs/nda/2012/125422Orig1s000MedR.pdf. Accessed October 30, 2013.

77. Pierro L, Zampedri E, Milani P, Gagliardi M, Isola V, Pece A. Spectral domain OCT versus time domain OCT in the evaluation of macular features related to wet age-related macular degeneration. Clin Ophthalmol. 2012;6:219-223.

78. Kim BT, Schwartz SG, Smiddy WE, et al. Initial outcomes following intravitreal ocriplasmin for treatment of symptomatic vitreomacular adhesion. Ophthalmic Surg Lasers Imaging Retina. 2013;44(4): 334-343.

79. NICE says yes to eye condition treatment in draft guidance. National Institute for Health and Care Excellence; 2013 [cited January 10, 2014]; Available from: http://www.nice.org.uk/newsroom/pressreleases/NICE YesEyeConditionTreatmentDraftGuidance.jsp. Accessed October 30, 2013.

80. Sebag J. Age-related differences in the human vitreoretinal interface. Arch Ophthalmol. 1991;109(7):966-971.

81. Wong SC, Capone A Jr. Microplasmin (ocriplasmin) in pediatric vitreoretinal surgery: update and review. Retina. 2013;33(2): 339-348.

82. Tsukahara Y, Honda S, Imai H, et al. Autologous plasmin-assisted vitrectomy for stage 5 retinopathy of prematurity: a preliminary trial. Am J Ophthalmol. 2007;144(1):139-141.

83. Clinical Trial of Intravitreal Microplasmin in Infants and Children Scheduled for Vitrectomy (MIC). ClinicalTrials.gov; 2013 [updated January 22, 2013; cited November 12, 2013]. Available from: http:// clinicaltrials.gov/ct2/show/study/NCT00986362?term=ocriplasmin\&r ank=12. Accessed October 30, 2013.

84. Sivaprasad S, Ockrim Z, Massaoutis P, Ikeji F, Hykin PG, Gregor ZJ. Posterior hyaloid changes following intravitreal triamcinolone and macular laser for diffuse diabetic macular edema. Retina. 2008;28(10): 1435-1442.

85. Laidlaw DA. Vitrectomy for diabetic macular oedema. Eye (Lond). 2008;22(10):1337-1341.

86. Jackson TL, Nicod E, Angelis A, et al. Vitreous attachment in agerelated macular degeneration, diabetic macular edema, and retinal vein occlusion: a systematic review and metaanalysis. Retina. 2013;33(6): 1099-1108.
87. A Multicenter Study to Compare Multiple Doses of Intravitreal Microplasmin. ClinicalTrials.gov; 2013 [updated July 4, 2013; cited November 12, 2013]. Available from: http://clinicaltrials.gov/ct2/show/ results/NCT00412451?term=ocriplasmin\&rank=7. Accessed October 23, 2013.

88. Weber-Krause B, Eckardt U. Haufigkeit einer hinteren Glaskorperabhebung bei Augen mit und ohne altersabhangiger Makuladegeneration. Eine echographische Studie [Incidence of posterior vitreous detachment in eyes with and without age-related macular degeneration. An ultrasonic study]. Ophthalmologe. 1996;93(6):660-665. German.

89. Ondeş F, Yilmaz G, Acar MA, Unlü N, Kocaoğlan H, Arsan AK. Role of the vitreous in age-related macular degeneration. Jpn J Ophthalmol. 2000;44(1):91-93.

90. Holekamp NM. The vitreous gel: more than meets the eye. Am J Ophthalmol. 2010;149(1):32-36.

91. Mennel S, Meyer CH, Schmidt JC. Der Einfluss des Glaskorpers auf die Pathogenese der altersabhangigen Makuladegeneration [The role of the vitreous in the pathogenesis of age-related macular degeneration]. Klin Monbl Augenheilkd. 2011;228(5):460-464. German

92. Mojana F, Cheng L, Bartsch DU, et al. The role of abnormal vitreomacular adhesion in age-related macular degeneration: spectral optical coherence tomography and surgical results. Am J Ophthalmol. 2008;146(2):218-227.

93. Schulze S, Hoerle S, Mennel S, Kroll P. Vitreomacular traction and exudative age-related macular degeneration. Acta Ophthalmol. 2008;86(5):470-481.

94. Koss MJ, Pfister M, Koch FH. Inflammatory and angiogenic protein detection in the human vitreous: cytometric bead assay. J Ophthalmol. 2011;2011:459251.

95. Pfister M, Koch FH, Cinatl J, et al. Zytokinbestimmung aus Glaskorperproben bei retinalen Gefasserkrankungen [Cytokine determination from vitreous samples in retinal vascular diseases]. Ophthalmologe. 2013;110(8):746-754. German.

96. Safety and Efficacy Study of Intravitreal Ocriplasmin in Subjects With AMD With Focal Vitreomacular Adhesion (MIVI-5). ClinicalTrials. gov; 2013 [updated June 6, 2013; cited November 12, 2013]. Available from: http://clinicaltrials.gov/ct2/show/study/NCT00913744?term=oc riplasmin\&rank=5. Accessed October 23, 2013.

97. Novack R. Ocriplasmin in exudative AMD (MIVI-005): Results of a prospective randomized clinical trial. Annual Meeting of the American Academy of Ophthalmology; November 16-19; 2013; New Orleans, Louisiana.

98. Tibbetts MD, Reichel E, Witkin AJ. Vision Loss After Intravitreal Ocriplasmin: Correlation of Spectral-Domain Optical Coherence Tomography and Electroretinography. JAMA Ophthalmology. 2014. Epub 2014/03/01.

99. Kim JE. Safety and Complications of Ocriplasmin: Ocriplasmin, Ocriplasmin; Oh, How Safe Art Thou? JAMA Ophthalmology. 2014. Epub 2014/03/01.
Clinical Ophthalmology

\section{Publish your work in this journal}

Clinical Ophthalmology is an international, peer-reviewed journal covering all subspecialties within ophthalmology. Key topics include: Optometry; Visual science; Pharmacology and drug therapy in eye diseases; Basic Sciences; Primary and Secondary eye care; Patient Safety and Quality of Care Improvements. This journal is indexed on Submit your manuscript here: http://www.dovepress.com/clinical-ophthalmology-journal
Dovepress

PubMed Central and CAS, and is the official journal of The Society of Clinical Ophthalmology (SCO). The manuscript management system is completely online and includes a very quick and fair peer-review system, which is all easy to use. Visit http://www.dovepress.com/ testimonials.php to read real quotes from published authors. 